\title{
IMPLEMENTASI AUGMENTED REALITY PADA APLIKASI ANDROID PEGENALAN GEDUNG PEMERINTAHAN KOTA BANDAR LAMPUNG
}

\author{
Rohmat Indra Borman ${ }^{1}$, Ansori ${ }^{2)}$ \\ 1) Sistem Informasi Akuntansi, Universitas Teknokrat Indonesia \\ ${ }^{2)}$ Informatika, Universitas Teknokrat Indonesia \\ Jl. H.ZA Pagaralam, No 9-11, Labuhanratu,Bandarlampung \\ Email : rohmat_indra@teknokrat.ac.id ${ }^{1)}$, ansoriaan72@gmail.com ${ }^{2)}$
}

\begin{abstract}
Abstrak
Augmented Reality (AR) merupakan teknologi yang memungkinkan melihat dunia nyata dengan bendabenda maya yang dimasukan secara real time dengan dunia nyata. Augmented Reality (AR) dapat dimanfaatkan dalam berbagai bidang, salah satunya dapat digunakan untuk pengenalan gedung pemerintahan. Kota Bandar Lampung tumbuh dan berkembang dengan cepat, baik fisik wilayah perekonomian sosial budaya dan jumlah penduduk dengan sering berkembangnya Kota Bandar Lampung membangun beberapa gedung-gedung dan pusat perkantoran. Dengan semakin banyak nya gedunggedung pemerintahan harus pula diimbangi dengan fasilitas informasi gedung pemerintahan dan lokasi gedung, agar masyarakat umum dapat mengenal gedung-gedung pemerintahan. Untuk mempermudah dalam mengenal gedung pemerintahan dapat menerapkan teknologi augmented reality untuk pengenalan gedung pemerintahan kota Bandar Lampung berbasis android, sehingga mampu memberikan pengalaman baru yang menarik dan interaktif bagi masyarakat, karena objek gedung yang ditampilkan berupa objek $3 D$ bukan lagi hanya gambar 2D-nya saja.
\end{abstract}

Kata kunci: augmented reality, $3 d$, gedung, pemerintahan.

\section{Pendahuluan}

Instansi pemerintah atau kantor pemerintah merupakan sebuah lembaga pemerintah yang bertujuan untuk menyiapkan, menyediakan, melaksanakan dan mewujudkan program dari pemerintah. Instansi Pemerintahan dalam menjalankan aktifitas kerjanya dilakukan di gedung instansI masing-masing. Begitu pula dengan Kota Bandar Lampung, untuk melayani masyarakat di bangun beberapa gedung-gedung dan pusat perkantoran, untuk mendukung segala kegiatan di kota Bandar Lampung khusus nya dibidang pemerintahan agar kota Bandar Lampung tertata dengan baik. Akan tetapi masyarakat umum masih belum banyak mengenal gedung-gedung pemerintahan. Maka dibutuhkan sebuah teknologi yang mampu membantu masyakakat dalam mengenal gedung-gedung pemerintahan dan mendapatkan informasi dari gedung tersebut.

Augmented Reality (AR) merupakan teknologi yang memungkinkan melihat dunia nyata dengan bendabenda maya yang dimasukan secara real time dengan dunia nyata. Pemanfaatan teknologi augmented reality pada saat ini telah meluas ke berbagai macam aspek seperti periklanan, sebagai navigasi, aplikasi industri dan rumahan, seni, sosial networking dan edukasi bakan teknologi augmented reality dipakai pada sebuah game yang pada saat ini sedang mengalami perkembangan, karena teknologi augmented reality sangat menarik dan mudah untuk di terapkan dan digunakan bagi penggunanya, contoh pada aspek edukasi dalam penyampaian sebuah informasi. Untuk membuat aplikasi augmented reality dibutuhkan dengan metode ini pengguna tidak perlu lagi menggunakan sebuah marker untuk menampilkan elemen-elemen digital. Untuk mempermudah dalam mengenal gedung pemerintahan kota Bandar Lampung maka dapat memanfaatkan teknologi augmented reality.

\section{Pembahasan}

\subsection{Augmented Reality}

Augmented Reality adalah sebuah teknologi yang menggabungkan suatu benda maya dua dimensi atau tiga dimensi ke dalam suatu lingkungan nyata tiga dimensi lalu memproyeksikan benda- benda maya tersebut kedalam waktu nyata (Azuma, 2011). Augmented Reality sebagai sistem yang memiliki karakteristik menggabungkan lingkungan nyata dan virtual, berjalan secara interaktif dalam waktu nyata dan integrasi dalam tiga dimensi (Milgram et al., 2011). Untuk menjalankan sistem AR, minimal terdiriatas kamera, perangkat monitor dan dalam kasus tertentu memerlukan perangkat khusus untuk berinteraksi dengan obyek virtual.

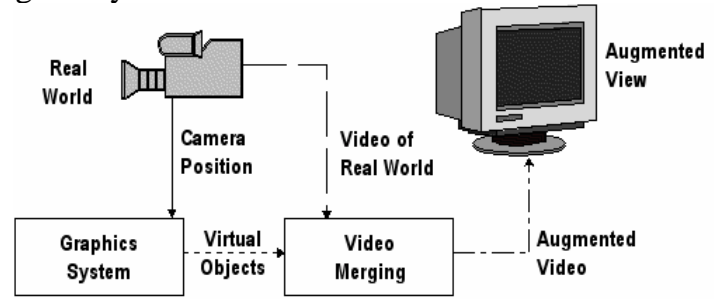

Gambar 1. Perangkat Pendukung Teknologi AR 
Augmented Reality memiliki cara kerja yang cukup sederhana dengan berdasarkan deteksi citra yang biasa disebut dengan marker. Sebagai contoh, sebuah kamera telah dikalibrasi dapat mendeteksi marker yang telah didesain, lalu setelah mendeteksi marker tersebut, kamera akan melakukan pencocokan dengan database yang telah dibuat sebelumnya. Dan jika hasilnya cocok, maka informasi dari marker akan digunakan menampilkan objek 3D yang telah didesain di depan layar penggunanya, tetapi jika marker tidak cocok dengan database maka informasi dari marker tidak akan dapat diolah.

Marker berfungsi sebagai media yang dibaca dan dikenal oleh kamera lalu dicocokan sehingga kamera akan merender objek 3D di atas marker (Wahyutama, 2013).

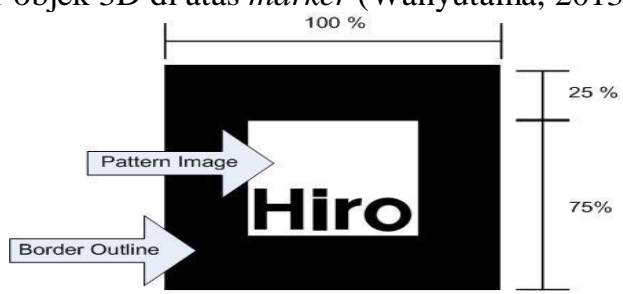

Gambar 2. Marker pada Augmented Reality

\subsection{Tahapan Implementasi Augmented Reality}

Dalam membuat aplikasi ini menggunakan software Unity. Unity adalah sebuah Tools yang terintegrasi untuk membuat bentuk objek 3D pada video games, atau untuk konteks interaktif lain seperti visualisasi arsitektur atau animasi 3D real-time (Nugraha, 2012). Berikut ini adalah tahapan dalam pembuatan aplikasi pengenalan gedung pemerintahan kota Bandar Lampung berbasis android dengan memanfaatkan Teknologi Augmented Reality.

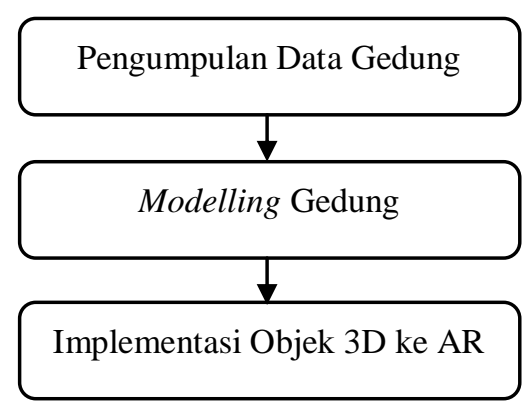

Gambar 3. Tahapan Pembuatan Aplikasi

Tahapan pertama adalah mengumpulkan data untuk penelitian, yaitu mencari desain dari gedung-gedung pemerintahan yang ada di Kota Bandar Lampung. Kemudian tahap berikutnya adalah pembuatan marker dari sample gedung yang nanti akan ditempel pada buku pengenalan gedung pemerintahan kota Bandar Lampung. Selanjutnya membuat model gedung pemerintahan kota Bandar Lampung. Kemudian Aplikasi ini akan mendeteksi marker yang ada di buku pengenalan gedung pemerintahan kota Bandar Lampung, lalu akan menampilkan berbagai bentuk 3D dari gedung pemerintahan kota Bandar Lampung. Di bawah ini adalah proses kerja aplikasi pengenalan gedung-gedung pemerintahan kota Bandar Lampung interaktif berbasis android dengan memanfaatkan teknologi augmented reality.

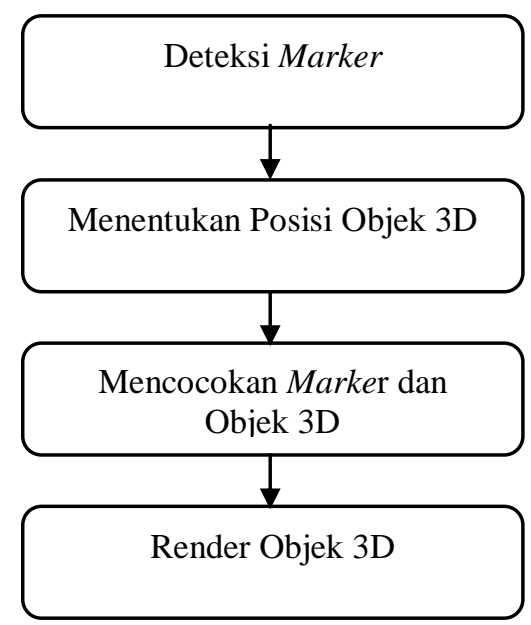

Gambar 4. Tahapan Pembuatan Aplikasi

Cara kerja aplikasi ini yaitu pertama kamera handphone mencari dan mendeteksi marker, kemudian marker yang telah di cetak di atas kertas putih tipis akan dibaca oleh alat/sistem kamera pada handphone. Langkah kedua adalah, kamera akan menentukan posisi dan orientasi marker 3D dan dikalkulasikan dengan kamera nyata. Langkah ketiga, kamera akan melakukan pencocokan marker dengan database yang telah dibuat sebelumnya. Jika hasilnya cocok, maka informasi dari marker akan digunakan menampilkan objek 3D yang telah didesain di depan layar penggunanya. Langkah ke empat, objek 3D gedung akan ditampilkan di layar yang muncul diatas marker.

\subsection{Rancangan Aplikasi Augmented Reality}

Prinsip kerja dari sistem ini adalah identifikasi marker melalui citra yang ditangkap oleh kamera yang nantinya ditampilkan dalam bentuk objek gedung secara 3D. Proses yang dilakukan meliputi pembacaan marker menggunakan kamera kemudian melakukan tahapan Pre Processing yaitu proses segmentasi untuk perbandingan marker dengan marker yang telah menjadi acuan sebelumnya. Bila marker merupakan citra yang memiliki kemiripan dengan data refrensi, maka hasil pengenalan citra itulah yang nantinya akan digunakan untuk menampilkan objek Gedung 3D nya.Pada dasarnya sebelum sistem ini berjalan maka sebelumnya harus dibuat markernya terlebih dahulu, untuk membuat markernya dapat dibuatnya dengan sebuah software editor gambar, yaitu Adobe Photoshop, setelah pembuatan marker selesai maka langkah selanjutnya adalah meng-uplod gambar tersebut pada situs develop milik vuforia, setelah selesai meng-upload pilih gambar yang sudah di upload tadi lalu pilih packing unity editor lalu download. Untuk jelasnya proses alurnya dapat dilihat pada gambar 5 . 


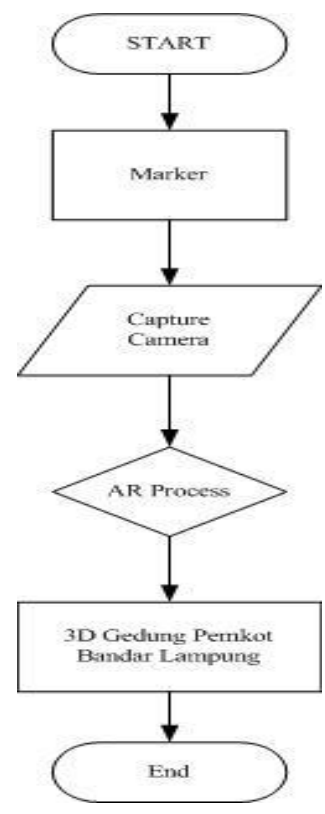

Gambar 5. Proses Alur Dari Sistem AR

Marker ditampilkan didepan kamera, lalu kamera akan membaca marker tersebut dan diolah. Bila marker yang dideteksi oleh kamera sesuai dengan marker yang telah menjadi acuan sebelumnya maka akan ditampilkan objek gedung pemerintahan 3D namun jika marker yang dibaca oleh kamera tidak sama dengan marker yang menjadi acuan maka process akan kembali melakukan pembacaan input image dari kamera. Flowchart augmented reality dapat dilihat pada gambar 6 dibwah ini :

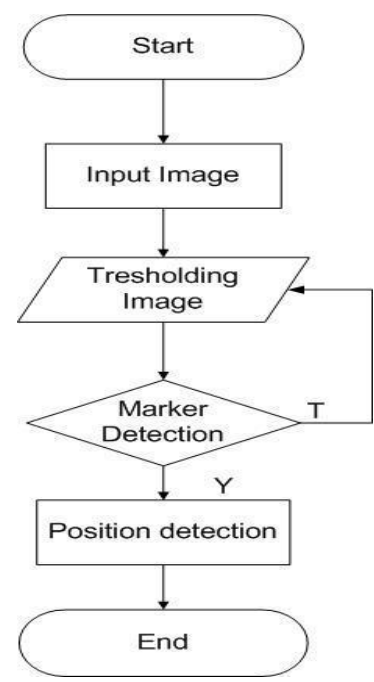

\section{Gambar 6. Flowchart Sistem AR}

Image yang dibaca oleh kamera akan dilakukan tresholding image, ini berfungsi sebagi metode sederhana yang akan memiliki nilai mean atau median dengan cara menghitung nilai pixel pada objek gambar. Dimana jika nilai pixel pada objek gambar juga harus lebih terang dari pada nilai rata-rata.

\subsection{Implementasi Aplikasi Augmented Reality}

Sebelum membuat aplikasi augmented reality dengan menggunakan aplikasi Unity maka pertama-tama adalah membuat objek 3 dimensi menggunakan software 3D Max lalu setelah selesai membuat objek tersebut di 3D Max maka langkah berikutnya adalah meng-extrak objek tersebut menjadi format .fbx terlebih dahulu. Tahap modelling atau pembuatan objek gedung 3D dilakukan satu persatu dengan software 3DMax sample Model gedung Pemkot Bandar Lampung diambil dari gambar yang ada pada brosur dan mengacu pada referensi yang dikumpulkan sebelumnya.

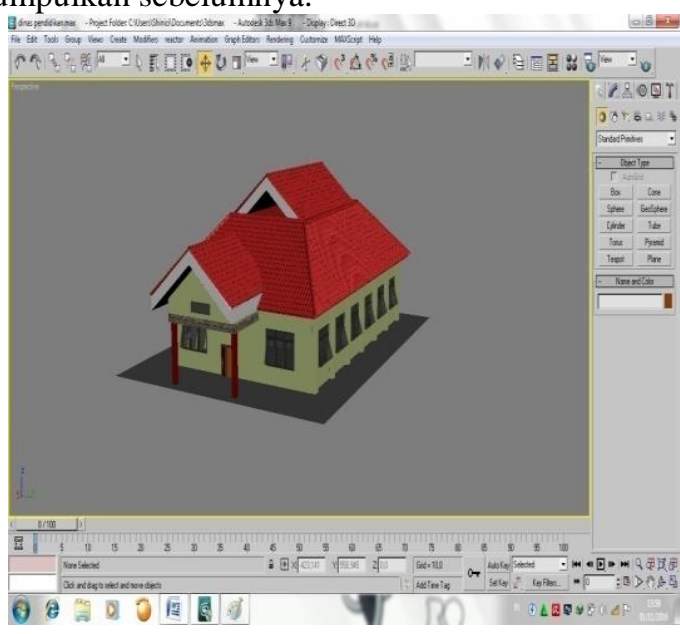

Gambar 7 Tahap Modelling Dalam 3D Max

Setelah proses modelling, selanjutnya adalah proses texturing atau memberi warna. Tujuan dari texturing tidak hanya membuat tampilan model menjadi realitis, tetapi juga meringankan proses modelling. Sample textur dapat diambil dari internet maupun yang sudah ada pada software.

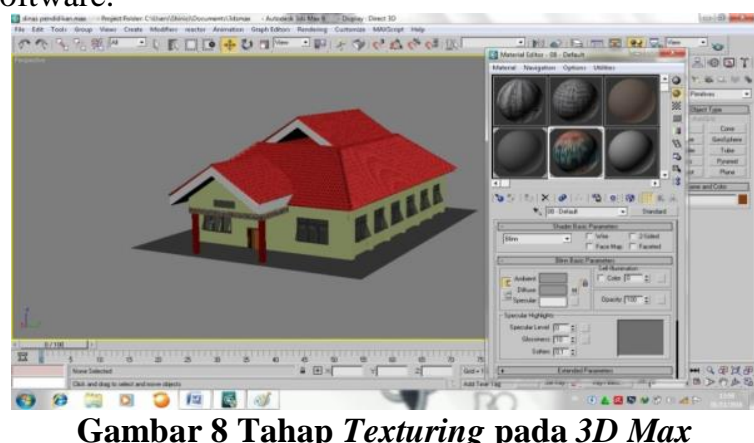

Berikutnya memasukan model 3D gedung yang sebelum nya kita buat dan export dengan menggunakan software 3D Max dengan cara buat folder baru pada folder Assets dengan cara klik kanan, Create, Folder, beri nama Folder tersebut lalu drag model 3D yang kita buat sebelum nya kedalam folder yang baru saja kita buat. Maka otomatis akan meng-import file model 3D tersebut, lalu drag objek 3D yang sudah kita import tadi kedalam ImageTarget yang ada di dalam kotak Hierarchy lalu sesuaikan ukuran objek 3D rumah tersebut tepat diatas 
marker.

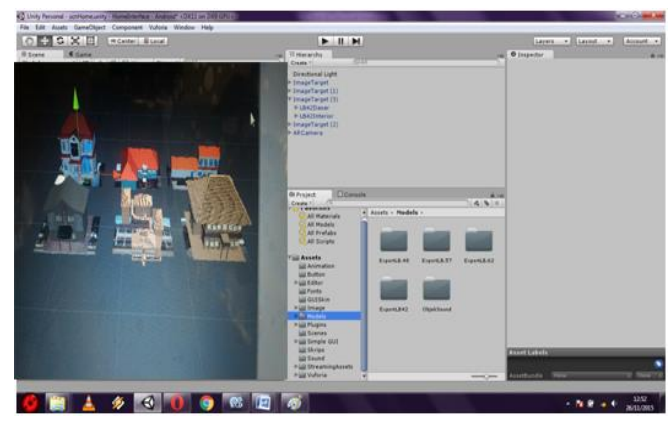

Gambar 9 Tampilan Setting Objek 3D

Setelah selesai setting model 3D sebagai aplikasi utama selanjutnya kita membuat script program agar aplikasi yang kita buat menjadi menarik dan interaktif. Bahasa pemerograman yang digunakan dalam projek ini adalah C\# dengan editor MonoDev. Untuk membuat nya langkah pertama yang dilakukan adalah membuat Folder Scripts pada Folder Assets dengan cara klik kanan pada folder Assets, Create, Folder lalu beri nama folder tersebut lalu masuk kedalam folder tersebut yang sudah kita buat lalu klik kanan Create, pilih C\#Script lalu beri nama dan double klik, maka akan muncul editor dari MonoDev tersebut.

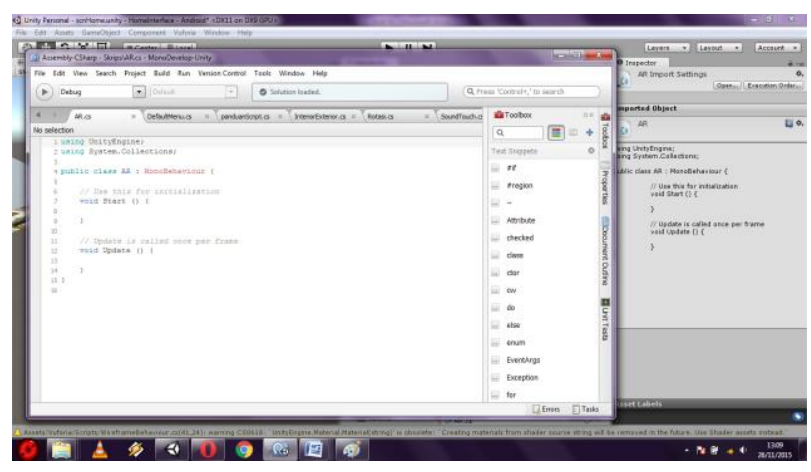

Gambar 10 Tampilan MonoDev

Berikuti ini salah satu contoh penerapa script untuk menu utama.

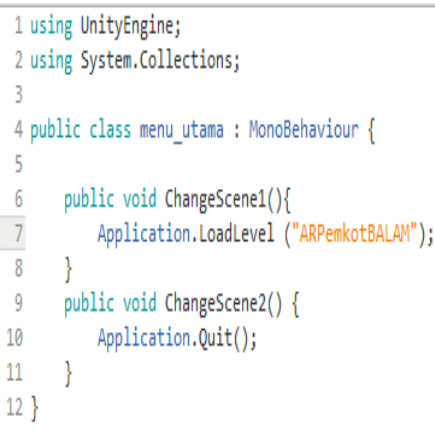

\section{Gambar 11 Script Menu Utama}

Halaman ini merupakan halaman cover dari buku. Berikut ini adalah gambar halaman cover buku :

\subsection{Hasil Aplikasi}

Berikut ini adalah hasil implementasi augmented reality pada aplikasi android pegenalan gedung Pemerintahan Kota Bandar Lampung.

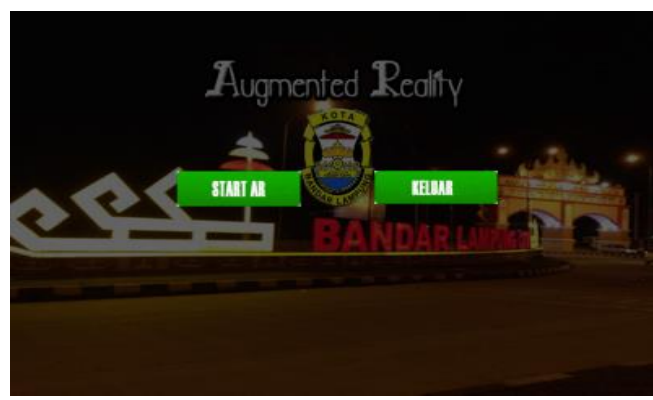

Gambar 12. Menu Utama Aplikasi

Ketika kamera diarahkan ke marker maka akan muncul gedung sesuai dengan yang ada di buku.

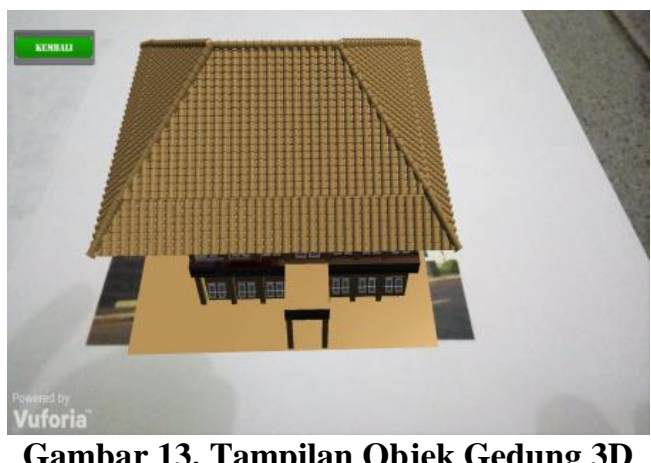

\section{Kesimpulan}

Setelah melakukan penelitian dan pembahasan mengenai pemanfaatan teknologi augmented reality untuk pengenalan gedung pemerintahan kota Bandar Lampung berbasis android, maka dapat diambil kesimpulanbahwa dengan buku pengenalan gedung pemerintahan kota Bandar Lampung yang menggunakan teknologi augmented reality ini, mampu memberikan pengalaman baru yang menarik dan interaktif bagi masyarakat, karena objek gedung yang ditampilkan berupa objek 3D bukan lagi hanya gambar 2D-nya saja.

\section{Daftar Pustaka}

[1] Azuma, R.T. 2011. A Survey of Augmented Reality. Presence: Teleoperators and Virtual Environments 6: 355-385.

[2] Jevri Setia Nugraha, 2012, Pembuatan Media Pembalajaran Pengenalan Tata Surya Dan Exoplanet Dengan Menggunakan Unity Untuk Sekolah Menengah Pertama. Program Studi Ilmu Komputer, Universitas Lampung

[3] Milgram, P., Takemura, H., Utsumi, A. \& Kishino, F. 2011. Augmented Reality: A class of displays on the reality-virtuality continuum. SPIE, 
Telemanipulator and Telepresence Technologies 2351: 282-292.

[4] Wahyutama, Febrian. 2013, Penggunaan Teknologi Augmented Reality Berbasis Barcode sebagai Sarana Penyampaian Informasi Spesifikasi dan Harga Barang yang Interaktif Berbasis Android Studi Kasus pada Toko Elektronik ABC Surabaya. Program Studi Sistem Informasi, Institut Teknologi Sepuluh November 